\title{
Strategic Buyers, Horizontal Mergers and Synergies: An Experimental Investigation ${ }^{*}$
}

\author{
Douglas D. Davis \\ Department of Economics \\ Virginia Commonwealth University \\ Richmond, VA 23284-4000 \\ dddavis@vcu.edu \\ Telephone: (804) 828-7140 \\ Fax: (804) 828-1719 \\ Bart J. Wilson \\ Interdisciplinary Center for Economic Science \\ George Mason University \\ Fairfax, VA 22030 \\ Telephone: (703) 993-4845 \\ Fax: (703) 993-4851 \\ bwilson3@gmu.edu
}

4 January 2006

\section{Abstract}

This paper reports an experiment designed to evaluate interrelationships between strategic buyers, market power and merger-induced synergies. The experiment consists of 40 posted-offer quadropolies. Treatments include the use of simulated or human buyers, seller consolidations and merger-induced fixed cost and unit cost synergies. In the simulated-buyer markets we observe behavior generally consistent with comparative static predictions: prices rise postmerger, and unit (but not fixed) cost synergies may exert some price-moderating effect. The addition of powerful buyers changes results markedly. Although prices are lower in the human buyer markets, outcomes are more variable and predicted comparative static effects are no longer observed.

\footnotetext{
* We thank without implicating Dan Kovenock, Paul Pecorino, Charissa Wellford and two anonymous referees for their helpful comments. Thanks also to Matthew Nuckols for programming assistance. Financial support from the U.S. Federal Trade Commission, the National Science Foundation and the Virginia Commonwealth University Faculty Excellence fund is gratefully acknowledged. The opinions in this paper are the authors' and do not necessarily represent the views of the Federal Trade Commission, or any individual Commissioner. Copies of instructions, the experimental data, and some supplementary tables are available at http://www.people.vcu/ ddavis.
} 


\section{Introduction.}

Most standard treatments of oligopoly behavior assume that buyers are passive, full demandrevealing agents. Although this assumption conforms well to a number of industrial contexts, in other situations buyers are often quite concentrated. Indeed, as Inderst and Wey (2003) observe, following the emergence of large retail chains, buyer concentration has become a critical feature of the relationship between manufacturers and retailers. Commentators have long suggested that strategic buyer behavior might affect market outcomes. The idea of countervailing power dates at least to Galbriath (1952), who argued that powerful buyers might offset the effects of seller market power. ${ }^{1}$

Countervailing power is particularly important for horizontal merger policy. In the last decade, unilateral effects analysis has become an important focus of horizontal-merger enforcement in the United States. ${ }^{2}$ Central to unilateral effects analysis is the notion that merger-related market power concerns emanate from changes in the strategic situation facing sellers. However, the pertinent models (e.g., Deneckere and Davidson 1985; Farrell and Shapiro, 1990, and Werden and Froeb, 1994) uniformly assume that buyers are passive. Powerful strategic buyers may affect importantly the predictions of such models. Not only may strategic buyers undermine seller market power both pre-merger and post-merger, they may also extract some or all of any merger-related synergies.

In antitrust investigations, consolidating parties often argue that large buyers will expropriate merger-induced cost efficiencies, and then pass these savings along to consumers in the form of lower prices. Consolidating parties make these claims even if the efficiencies involve only unavoidable fixed costs. ${ }^{3}$ For example, in FTC v. Cardinal Health and FTC v. McKesson Corp., the third and first largest pharmaceutical wholesalers proposed to purchase, respectively, the second and the fourth largest wholesalers. The plaintiffs argued that the consolidations would generate hundreds of millions of dollars of merger-specific fixed-cost savings, the vast bulk of

\footnotetext{
${ }^{1}$ Empirical studies documenting the effects of countervailing power include Lustgarten (1975), Chipty (1995), and, Chipty and Snyder (1999).

${ }^{2}$ In the 1992 revision of their Horizontal Merger Guidelines the United States Department of Justice and the Federal Trade Commission added to the traditional cooperative effects enforcement focus a unilateral effects focus.

${ }^{3}$ That fixed cost savings often loom large as a component of consolidating parties' case for cognizable efficiencies is unsurprising. Although some consolidations may allow rationalization of production lines, or other changes that reduce unit production or distribution costs, overhead savings attributable to the elimination of duplicative central administrative offices represents an almost generic merger-induced efficiency. Further, given the often immense costs of reorganizing the administrative structure of a consolidating firm, administrative fixed costs are most plausibly viewed as unavoidable in any reasonable operating horizon.
} 
which would be passed along to consumers. An important part of the respondent's case was that the relevant market included very large buyers, and that the price reductions would be extracted by powerful buyers who would not settle for less.

The effects of countervailing buyer power are not well understood either theoretically or empirically. Understandably, the U.S. Horizontal Merger Guidelines articulate no standard for identifying circumstances where buyers may be expected counteract the anti-competitive effects of mergers. Courts in the United States, however, have not been entirely unsympathetic to arguments that countervailing power can offset the effects of increased seller concentration. For example, in United States v. Country Lake Foods, Inc., the court refused to enjoin a merger where three large customers accounted for $90 \%$ of all fluid milk sales in the relevant market. ${ }^{4}$ Some research also suggests that other countries are more receptive to the notion that countervailing power can balance increasing seller concentration. Dobson and Waterman (1997) contend that increased concentration in the British retail industry relative to that in the United States reflects a more sanguine view in Great Britain about the ameliorative effects of countervailing buyer power.

This paper reports an experiment conducted to shed some light on the interrelationships between powerful buyers, market power, and merger-induced efficiencies. Laboratory methods present a useful way to generate insights into the effects of strategic buyers, for two reasons. First, for markets with strategic buyers, no counterpart to the standard Bertrand and Cournot models exists that is both analytically tractable, and describes the effects of withholding reasonably well. Adding strategic buyers complicates the analysis, because the potential for withholding obfuscates critical features of the underlying game, such as the price formation mechanism (bargaining, posted prices, etc.), the game's extensive form, and the appropriate information structure. Analyzing the possibility of strategic buyer withholding also requires the contemplation of repeated interactions, since foregoing purchases in one time period can only be rational if such behavior elicits more desirable prices in future periods. Experiments are a useful way to initiate theoretical research on these issues, as they have the potential to provide guidance to theorists about how such markets work.

\footnotetext{
${ }^{4}$ Other factors important in the decision to not enjoin the merger include low entry barriers and a complete absence of brand differentiation.
} 
Second, inherent data problems impede the evaluation of interrelationships between mergers, synergies and strategic buyers with naturally-occurring data. In natural contexts both costs and merger-associated cost synergies are observable only indirectly. A number of factors other than cost changes or changes in the strategic context induced by the merger may drive postmerger prices. The relevant dataset may also suffer from selection bias, as antitrust authorities often challenge the very cases that are of primary interest. In the laboratory, costs and the magnitude and type of cost savings can be controlled. All consolidations are legal and both market power and countervailing buyer behavior can be observed directly.

As a preview, we find that in markets with passive (simulated) buyers standard theoretical predictions organize outcomes reasonably well. In these markets, prices tend to increase following consolidations, and synergies exert the predicted effects: fixed cost savings clearly do nothing to affect merger-induced market power changes, and, while the data are not unambiguous, some evidence suggests that unit cost synergies may exert a price-tempering effect. However, the addition of large human buyers changes market outcomes dramatically. Median prices in the large-buyer markets fall below median prices in the simulated-buyer markets both pre-merger and post-merger, and prices tend not to increase post-merger. Mean trading efficiency in the real buyer markets also falls, as buyers persistently forego profitable purchases in an effort to drive prices down. Finally, while considerable variability characterizes outcomes in the real-buyer markets, buyers do, in several instances extract the bulk of both fixed and unit cost synergies created by a consolidation.

We organize the presentation as follows. Section 2 below reviews the related literature. Section 3 sketches out a simple model that motivates our experimental design, and serves as the foundation for our conjectures regarding experimental results. Section 4 describes the experimental design and procedures, and section 5 presents our experimental results. We conclude with a brief sixth section.

\section{The Related Literature.}

A growing theoretical literature addresses the effects of buyer power on pricing outcomes. Most of these papers evaluate the effects of buyer size in a static bilateral bargaining context, either under Nash bargaining (e.g., Chipty and Snyder, 1999, Horn and Wolinsky, 1988, or using specific bargaining procedures that gives rise to a Shapley value (e.g,. Inderst and Wey, 
2003, Stole and Zwiebel, 1996a,b). ${ }^{5}$ More nearly pertinent to the current study is Groh (2004) who analyzes bilateral bargaining in a repeated Bertrand-Edgeworth game, where sellers post prices on a take-it-or-leave-it basis for single units to randomly-matched buyers. Among other results, Groh identifies an "optimal equilibrium” for buyers in which credible withholding threats result in the buyer extracting all of the available surplus. Groh also shows that giving a buyer an "outside option” of shopping elsewhere can reduce the buyer's optimal equilibrium payoff, a result which suggests that withholding opportunities may benefit buyers only little. ${ }^{6}$ While Groh's analysis is provocative, the bilateral nature of negotiations in his game make it only indirectly relevant to the multilateral market contexts that underlie antitrust policy. ${ }^{7}$ To our knowledge no theoretical work considers countervailing buyer power in a multilateral market context with posted prices.

Withholding behavior has been has been the subject of extensive attention by experimentalists, most prominently in the ultimatum game. The persistent behavioral tendency for 'proposers' (sellers) and 'responders' (buyers) to split the surplus far more equally than predicted in the static Nash equilibrium has been a source of considerable debate (see, for example the discussion in Roth, 1995). ${ }^{8}$ Groh's baseline bargaining environment is a repeated version of the ultimatum game. Regardless of the factors motivating surplus divisions in the static game, Groh's analysis suggests that repetition (at least indefinite repetition) should move the division of the surplus in the favor of buyers, as repetition creates for responders the possibility of credible threats to forego divisions offered on insufficiently attractive terms. Slembeck (1999) reports an experiment that provides some insight into the effects of repetition

\footnotetext{
${ }^{5}$ A general result in this literature is that the capacity of large buyers to elicit discounts turns on the curvature of the surplus function. In particular, large buyers elicit lower prices in an equilibrium if the surplus function is convex (as would be typically the case, for example, when sellers face increasing marginal costs). Recently Normann, Ruffle and Snyder (2003) develop a similar result in a static game in a posted-bid context. These authors also report an experiment that supports this prediction.

${ }^{6}$ This latter result is driven by the assumptions (a) that buyers see only a single price quote each period, and (b) that sellers do not know the buyers' history of accepting or rejecting contracts. Reducing switching costs encourages buyers to "defect" from a strategy of buying only at very low prices by making a purchase and then going to a pool of unmatched sellers in the next period. A seller treats any new match as a new customer, and posts a high initial price. Thus, the possibility of switching effectively reduces the strength of seller punishments and thus raises the optimal equilibrium price.

${ }^{7}$ Repeated contacts between specific buyers and sellers are a defining feature of the "customer markets" analyzed by Groh. In the standard oligopoly models that underlie antitrust policy sellers post prices publicly to all buyers. Thus, sellers compete directly with each other, as well as with buyers.

${ }^{8}$ Many commentators (e.g,. Guth et al., 1982) attribute the tendency for buyers and sellers to split the available surplus to some concern for "fairness", while others (e.g., Hoffman, et al., 1994) argue that context, and perceived entitlements to property rights drive observed outcomes.
} 
of the ultimatum game. Comparing the results of a "fixed pairs" treatment, where participants were re-matched in a series of 20 consecutive rounds with a parallel 20-round "rotation pairing” treatment, Slembeck finds that proposed offers fall only marginally (by just 1 percentage point). However, responders' rejection rates increased by about 10 percentage points in the repeated treatment relative to the baseline treatment. ${ }^{9}$ Slembeck also finds that personal characteristics of the players are much more likely to influence the dynamics of play in the fixed pairs treatment. Persistently rematched “tough” proposers and “tough” responders, for example, are more likely to suffer disagreements than "fair" players.

Slembeck’s observations regarding repetition in ultimatum games appear to extend to more complicated multi-agent repeated posted-offer markets. Ruffle (2000) and Engle-Warnick and Ruffle (2003) find that fully informed posted-offer buyers often engage in very considerable withholding. As a consequence, surplus extraction rates ("trading efficiencies") were in some markets considerably below levels normally observed in posted-offer markets, and prices in some markets fell below the range of competitive equilibrium predictions. Further, outcomes were characterized by very considerable variability across markets, suggesting that the personal characteristics of both buyers and sellers may importantly affect outcomes in repeated fullinformation markets. ${ }^{10}$

Theoretical and experimental analyses of unilateral market power represent a second strand of pertinent literature. As is well known, in a Bertrand-Edgeworth pricing game (with passive buyers) seller capacity constraints can raise the static Nash equilibrium price from one determined by the intersection of market supply and demand curves, to a mixing distribution of prices that strictly exceed the competitive outcome (see, e.g., Kreps and Schienkman, 1983,

\footnotetext{
${ }^{9}$ All participants knew that the game would last exactly 20 periods. Thus, the standard analysis would suggest that strategic withholding is not part of an equilibrium strategy for a responder. If each subgame of a finitely repeated game has the same unique equilibrium, that strategy defines the unique subgame perfect equilibrium strategy for the finitely repeated game.

${ }^{10}$ Common knowledge about costs and values is a critical element in the design of the Ruffle (2000) and EngleWarnick and Ruffle (2003) experiments. Absent information about underlying costs and values, Davis and Williams (1990) find that buyers appear incapable of recognizing their capacity to manipulate the terms of trade. In a "Buyer Market Power" design, where the withholding of a single unit by either of two buyers shifts downward substantially the equilibrium price Davis and Williams find that buyers never recognize their price-manipulating capacity. To the contrary, buyers almost uniformly purchased all units available, even those units that were only marginally profitable. Each of four markets conducted converged to competitive predictions, and buyers consummated all but 10 of 521 possible contracts
} 
Osborne and Pitchik, 1986 and Davidson and Deneckere, 1986). ${ }^{11}$ The reasoning driving results in models of this type underlies standard unilateral effects analysis; horizontal consolidations change the residual demand conditions for the remaining firms, thus altering the support of the relevant mixing distributions. ${ }^{12}$ Related experimental research by Davis and Holt (1994) indicates that sellers recognize and exercise such unilateral market power when a horizontal merger creates the necessary imbalances between residual demand and supply. ${ }^{13}$

A third strand of pertinent literature evaluates the effect of cost savings on market performance. As a theoretical matter, unit cost reductions can generate lower prices, and expanded seller profits. ${ }^{14}$ Thus, unit-cost synergies can attenuate merger-induced market power increases. Werden and Froeb (1994) develop a policy model that considers explicitly the tradeoffs between merger induced market power increases and cost synergies in a differentiated product Bertrand setting. ${ }^{15}$ Results of laboratory experiments by Davis and Wilson (2000, 2006) suggest that unit-cost synergies can exert a price-damping effect. ${ }^{16}$ In contrast to unit costs, unavoidable fixed costs do not affect pricing decisions, and thus should not affect pricing, even though fixed cost savings may increase seller profits. Again, using laboratory evidence in a

\footnotetext{
${ }^{11}$ Cripps and Ireland (1988) analyze such a game in a "box" structure that more closely resembles our experimental setup.

${ }^{12}$ Holt (1989) draws explicitly the link between market power as defined in the Guidelines, and seller incentives to raise prices induced by capacity constraints.

${ }^{13}$ Here we focus on price-setting (Bertrand) environments. Due to the relative subtlety of a quantity-setting context, Cournot markets tend to be considerably more volatile than Bertrand markets (e.g., Davis, Reilly and Wilson, 2003) and sellers find market power more difficult to recognize. Also in Cournot markets, merging parties typically earn less than they earned as independent sellers (see e.g., Farrell and Shapiro, 1990), a factor that complicates the laboratory analysis of mergers in Cournot markets. In experimental studies, Wellford (1990) and Davis (2002) find little evidence that sellers recognize the change in power induced by a horizontal consolidation. On the other hand, Huck et al. (2001) report some evidence that sellers eventually reduce aggregate quantities post-merger, even though the merging parties do not reduce output as much as predicted.

${ }^{14}$ Unit cost synergies reduce equilibrium prices when firms face no capacity constraints, and in specialized cases of capacity constraints, such as the single step demand function used here. More generally, however, unit cost synergies may not reduce equilibrium prices for capacity-constrained sellers in a Bertrand-Edgeworth price setting game. As Deneckere and Kovenok (1996) demonstrate, given constant unit costs, a concave revenue function and efficient rationing, a small synergy to only one of the firms will leave unchanged the mixing distribution for the seller enjoying the cost reduction, and will raise the mean of the mixing distribution for the other firm.

${ }^{15}$ Farrell and Shapiro (1990) also evaluate the price mitigating effects of unit cost savings on mergers, but in a Cournot rather than in a Bertrand context.

${ }^{16}$ Similarly, in a Cournot environment Wellford (1990) finds some consistent evidence that sellers increase quantities (and lower prices) in response to economies of scale, despite failing to exercise merger-induced market power.
} 
passive buyer context, Davis and Wilson (2000) find that a fixed cost synergy leaves pricing unaffected. $^{17}$

To the best of our knowledge, the effects of strategic buyers on merger-induced seller market power increases, as well as on the price-ameliorating effects of merger-induced synergies has not been explored, either theoretically or empirically in the laboratory.

\section{Mergers, Synergies and Strategic Buyers: Reference Predictions and Some Conjectures.}

This section develops a simple market structure to generate reference predictions given passive buyers, and then offers some informal conjectures regarding behavior given strategic buyers. The section consists of three parts. Subsections 3.1 and 3.2 generate static predictions in a standard Bertrand-Edgeworth context regarding the effects of mergers, and synergies, respectively. Then subsection 3.3 lays out the cost and information conditions in the repeated game with large, powerful buyers, and offers some informal conjectures regarding the consequences strategic buyer behavior on market power and synergies.

3.1. Mergers and Synergies with Passive Buyers. Consider a market with four symmetrical sellers, $S 1, S 2, S 3$, and $S 4$, each of whom may sell up to two units each period, in integer quantities. Sellers produce under conditions of a constant unit cost $c$, and an unavoidable fixed cost $F .^{18}$ The demand side of the market consists of seven units, each of which will be purchased at prices up to and including a reservation value $v$. The stage-game is a standard Bertrand-Edgeworth pricing game, with simultaneous seller pricing decisions, followed by purchases from a fully revealing buyer, who buys the lowest priced units first, and in the case of a tie rotates purchases among the sellers posting the same price.

The left panel of Figure 1 illustrates this market for the case where $c=\$ 2, v=\$ 6$ and $F=$ \$3. (To facilitate the presentation of our experimental design, we will use these parameter values to generate numerical predictions throughout this section.) Notice from the intersection of supply and demand arrays that in a competitive outcome, sellers post a competitive price $p_{c}=c$

\footnotetext{
${ }^{17}$ Buchheit and Feltovich (2005) report an experiment suggesting that changes in sunk costs do exert some effect on pricing decisions, although the relation between sunk cost levels and prices these authors report is, rather curiously, non-monotonic.

${ }^{18}$ Thus, fixed costs here are essentially sunk. We defer to future analysis the interesting case of avoidable fixed costs (where fixed costs are incurred only if the firm produces a positive quantity). Assuming unavoidable fixed costs both simplifies the analysis, and is more realistic in markets where sellers find impractical the contemplation of dismissing and rehiring overhead staff across pricing decisions.
} 
and lose their fixed cost outlay $F$ each period. To earn zero profits (in expectation), sellers must receive breakeven price $p_{b e}=\$ 3.71$ each period. ${ }^{19}$

Notice, however that, $p_{c}=c$ is not a Nash equilibrium for the stage game. Given the aggregate excess supply of one unit, any seller can be certain to sell at least one unit at reservation price $v$, and earn $(v-c)-F$. Neither is $p=v$ a Nash equilibrium, since only seven of the eight available units sell each period. Following the extensive theoretical literature on Bertrand-Edgeworth competition (e.g., Kreps and Scheinkman, 1983 and Osborne and Pitchik, 1986) the unique symmetric equilibrium for this game involves mixing over the range of prices $\left\{p_{\min , v}\right.$, where

$$
p_{\min }=(v+c) / 2=\$ 4.00 .^{20}
$$

For emphasis, we highlight the range $v$ and $p_{\min }$, as the vertical bar on the left side of Figure 1 . In the equilibrium, sellers price according to the cumulative density function

$$
H(p)=\sqrt[3]{\frac{2 p-c-v}{p-c}}, p \in[4,6] .
$$

Most of the pricing density for $H(p)$ lies close to the lower bound of the mixing distribution. For example, setting $H(p)=.5$, the median of the density distribution $\tilde{p}=\$ 4.43$.

Consider now the effects on static predictions of a pair of consolidations that reduces the number of sellers from four to two. The supply and demand arrays shown on the right side of Figure 1 illustrate. Absent any synergies, the consolidations simply double the size of the merging firms. The consolidations increase market power because each seller now sells $75 \%$ of his or her capacity with certainty ( 3 of 4 units available) rather than $50 \%$ ( 1 of 2 units).

\footnotetext{
${ }^{19}$ To determine $p_{b e}$, solve $3\left(2\left(p_{b e}-c\right)-F\right)+\left(\left(p_{b e}-c\right)-F\right)=0$, with $c=\$ 2$ and $F=\$ 3$.

${ }^{20}$ The constraints imposed by constant earnings and identical distributions make uniqueness in symmetric strategies obvious. While we are unable to rule out the existence of asymmetric mixing equilibria for the four seller game, we would be surprised to learn that asymmetric equilibria existed. Analyzing a two-seller pricing in a "box" design that closely parallels the market structure examined here, Cripps and Ireland (1988) establish uniqueness of the symmetric mixed strategy equilibrium. We expect that this such result extends to the case of four identical sellers. More generally, we observe (as did Kreps and Scheinkman, 1983 and Osborne and Pitchek, 1986) that security earnings in the symmetric mixing equilibrium are unique. Thus, finite repetition of the game creates no additional subgame perfect equilibria, since no threat of earnings different from those expected in the symmetric mixing equilibrium exist. Of course, as is well known, indefinite repetition creates additional equlibria. Finally, we observe that our method of identifying the equilibrium for this 4-seller game follows that procedure set out by Holt and Solis Soberon (1992) for calculating equilibrium mixing distributions multi-seller games using the "step-function" demand and supply curves that are typical in laboratory posted-offer markets.
} 
Reasoning as in the four seller case, the consolidated sellers randomize over a range from $v$ to $\rho_{\min }$ where,

$$
\rho_{\min }=(3 v+c) / 4=\$ 5.00 \text {. }
$$

In the post-merger equilibrium, sellers price according to the cumulative distribution

$$
M(\rho)=\frac{4 \rho-3 v-c}{\rho-c}, \rho \in[5,6] .
$$

(We use $\rho$ to denote the post-merger price.) Setting $M(\rho)=.5$ yields a median price $\tilde{\rho}=\$ 5.43$.

Experimental evidence suggests that in market games of this sort, sellers recognize and respond to conditions that create unilateral market power (see. e.g., Davis and Holt, 1994, and Wilson, 1998). We are, however, aware of no experiments that examine the response of sellers to conditions that increase pre-existing market power. This is a rather interesting question, as the predicted comparative static response requires sellers to alter their distribution of random responses. This question forms our first conjecture.

Conjecture 1: Absent strategic buyers, the increase in market power induced by consolidating sellers will increase prices significantly.

3.2 Synergies and Merger-Induced Market Power. Consider now the same pair of consolidations, but suppose that as a consequence of the mergers, the consolidating firms enjoy a large merger-induced synergy that reduces fixed costs. Specifically, assume that that fixed costs for each pair of consolidating firms falls by $\$ 4.50$, from a (combined) $\$ 6$ pre-merger to $\$ 1.50$. The left panel of Figure 2 illustrates. Notice that due to the reduction in fixed costs, average cost curves for each of the two sellers fall from $a c$ to $a c^{\prime}$. (We will use the apostrophe to denote variables involving a fixed cost efficiency post-merger.) Relatedly, the breakeven price falls from $p_{b e}=\$ 3.71$ to $\rho_{b e}^{\prime}=\$ 2.43$. Nevertheless, the equilibrium mixing distribution remains unaffected (Note in equations (2) and (4) that fixed costs play no role in the sellers' mixing distributions). This observation underpins the reticence of antitrust authorities to consider fixed cost synergies, because such savings do not affect equilibrium pricing behavior.

Alternatively, suppose that the merging firms enjoy unit cost synergies of a total magnitude comparable to the fixed cost reduction just considered. The supply and demand arrays shown in the right panel of Figure 2 illustrate. In the figure unit costs fall from $c=\$ 2$ pre- 
merger to $c_{\boldsymbol{u}}=\$ 0.71$ post-merger. ${ }^{21}$ As with the fixed cost reduction, the unit cost savings shift downward both the average cost curves and the breakeven price. However, unlike fixed cost savings, a comparable unit cost efficiency reduces the median of the mixing distribution from $\tilde{\rho}=\$ 5.43$ to $\tilde{\rho}_{u}=\$ 5.24 .^{22}$

Analytically the equilibrium mixing distribution for the static post-merger game, shown in equation (4), makes clear the effect of unit cost synergies on prices. Unit costs $c$ are a negative term both in the numerator and denominator of (4). Thus, reductions in $c$ increase the cumulative density at any price $\rho<v$. We summarize the differing effects of fixed cost and unit cost synergies on static equilibrium predictions as a second conjecture.

Conjecture 2: Absent strategic buyers, a unit cost synergy reduces post-merger prices. However a fixed cost synergy of comparable magnitude does not affect post-merger prices.

Prior to considering the possible effects of countervailing buyer power, we observe that the predicted effects of unit cost savings here are relatively small. Despite a $\$ 1.29$ per unit cost savings, the median of the equilibrium mixing distribution falls only $\$ .19$ (from $\$ 5.43$ to $\$ 5.24$ ), far less than the $\$ 1.00$ increase in the median of the equilibrium mixing distribution generated by reducing the number of sellers from four to two.

In Davis and Wilson (2000, 2006) we identify some conditions where sellers follow underlying static Nash equilibrium predictions in responding to unit cost synergies. Davis and Wilson (2000) reports an asymmetric three seller design, where a unit cost synergy changes the large seller's unique static equilibrium strategy from one characterized by randomization over a range of supra-competitive prices, to a pure strategy posting at the competitive price. Davis and Wilson (2006) examines the effects of unit cost synergies in a continuous-unit differentiated product Bertrand game, where all reference equilibrium predictions are in pure rather than mixed strategies, and where the associated merger reduces number of sellers from four to three. The effect investigated here is considerably more sutble.

Design constraints drive the comparatively subtle predicted unit cost synergy effect. (Indeed, reducing unit costs to zero, reduces the median of the mixing distribution only to $\$ 5.14$.)

\footnotetext{
${ }^{21}$ The savings of $\$ 1.29$ per unit generates a total expected savings of $\$ 4.50$. Each seller sells 3.5 units each period in expectation. $3.5 \times(\$ 2-\$ 0.71)=\$ 4.50$.

${ }^{22}$ To generate the lower bound of the mixing distribution, insert $c_{u}=\$ 0.71$ into (3) to generate $\rho_{\min _{u}}=\$ 4.67$. $\tilde{\rho}_{u}$ is derived from (4) by setting $\mathrm{M}(\rho)=.5$ when $c=c_{u}$.
} 
Enhancing the predicted responses of sellers to unit cost synergies requires the use of more complicated demand and/or unit cost conditions, where an increased number of units trade each period. These conditions undermine both the transparency and the potential scope of price effects in the powerful buyer markets described in the next subsection. Further, increasing the number of units traded per period would increase period length, and thus would reduce the number of trading periods that could be conducted per session. In any case, a failure to observe predicted responses to unit cost synergies, does not necessarily imply confusion on the part of the randomizing sellers. Other effects, particularly tacit collusion among the post-merger duopolists, may dominate the relatively small predicted unit cost synergy effects.

\subsection{Buyer Withholding, Market Power and Synergies. Rational buyer withholding} requires indefinite repetition of the above game. Buyers must balance the costs of failing to make profitable purchases in a current period against the expected gain of inducing lower prices in future periods. Suppose we consolidate the buyer side of the market shown in Figures 1 and 2 into of a pair of buyers, $B 1$ and $B 2$, each of whom is "powerful” in the sense that they control at least three units (e.g., give $B 13$ units one period, and 4 units the next). Thus, in any period, via withholding, each buyer can unilaterally preclude half the sellers from completing a transaction, both pre-merger (where the highest pricing 2 of the 4 sellers will sell no units) and post-merger (where the highest pricing of the 2 sellers will trade no units). Assume that the sellers know that the buyer side of the market consists of two powerful buyers, and that all agents know, as public information, each seller's unit and fixed costs, and each buyer's values. ${ }^{23}$ The structure of moves is the same as before, except that the buying sequence consists of shopping decisions by two buyers, rather than one, and each buyer may elect to forego profitable purchases in a period in an effort to elicit lower prices in subsequent periods. Specifically, each period sellers $S 1$ to $S 4$ simultaneously post prices, which are displayed as public information. Then one of the buyers, $B 1$ or B2 is randomly selected to "shop." The selected buyer may purchase up to their capacity each period, as long as prices are less than or equal to their common unit value, $v$. When the first

\footnotetext{
${ }^{23}$ Any equilibrium analysis of this game would require specification of a discount factor or a probability of termination. We omit this from the present characterization because we do not attempt to solve for an equilibrium, and because we induced no specific probability of continuation in our experiment.
} 
buyer finishes, the remaining buyer makes purchase decisions. ${ }^{24}$ Sellers observe how many units they sold in a period. However, sellers observe neither the total number of units sold, nor which buyer made purchases from them. As mentioned in the introduction, analyzing the equilibrium for such a game is a formidable undertaking that extends well beyond the scope of this paper. As an alternative we offer the following three informal conjectures regarding the addition of strategic buyers in this market game.

Conjecture 3: Inserting powerful human buyers into the above environments reduces prices, both pre-merger and post-merger.

Conjecture 4: Inserting powerful human buyers into the above environments reduces trading efficiency. ${ }^{25}$

Conjecture 5: Given powerful human buyers, a unit cost synergy reduces post-merger prices. However a fixed cost synergy of comparable magnitude does not affect post-merger prices.

Conjectures 3 is motivated by the possibility that demand-side withholding creates in buyers a bargaining power not available with simulated buyer decisions. At some level, it would be surprising if the introduction of this potentially powerful action did not result in reduced seller prices. Conjecture 4 addresses the amount of withholding we might expect to observe in the repeated game. Although we have not attempted to characterize the equilibrium set for this repeated Bertrand-Edgeworth game with real buyers, we would expect that the equilibrium set includes "efficient" elements, where withholding does not occur: Sellers, recognizing the credibility of buyers' threats, should eventually reduce prices sufficiently to avoid "punishment." Thus, as a reference prediction, we evaluate behavior relative to these efficient outcomes.

We emphasize that Conjecture 4 is a reference prediction. As mentioned above in section 2, previous experimental evidence with powerful buyers (responders) reported by Engle-Warnik and Ruffle (2002), Ruffle (2000) and Slembeck (1999) suggest that withholding may cause

\footnotetext{
${ }^{24}$ The purchase decisions of one buyer are not directly revealed to the other. Buyers can, however infer each other's purchase decisions with reasonable accuracy from seller "out of stock" messages. In the event of withholding, however, sellers, have no way of discerning whether a lack of sales was due to withholding by $B 1, B 2$ or by a combination of both $B 1$ and $B 2$.

${ }^{25}$ In market experiments, the term "efficiency" typically refers to the percentage of the available buyer and seller surplus extracted by trade in a period. To avoid confusing this term with the efficiencies that can mitigate antitrust concerns about mergers, in what follows we use the term "trading efficiencies" to refer to surplus extraction rates, and "synergies" to refer to efficiencies associated with a consolidation.
} 
persistent trading efficiency losses in some markets. Sessions in our experiment, however, are of considerably longer duration than those in the just-mentioned experiments. ${ }^{26}$

Conjecture 5 simply restates conjecture 2 for the case of real buyers. The capacity of powerful buyers to extract both fixed and unit cost synergies is a primary motivation for our investigation.

Prior to proceeding, we observe that the possibility of buyer withholding does not obviously tilt equilibrium outcomes in the favor of buyers. For example, adapting the analysis by Groh (2004) to the present context might suggest that countervailing power does not affect the equilibrium at all. In Groh's analysis the credibility of buyer withholding depends on the buyer's outside options, as well as on assumptions regarding information conditions. In particular, withholding is credible (and thus elicits lower equilibrium prices) when the buyer has high switching costs and when sellers know a buyer's trading history. These features are absent from our markets, and their absence may undermine the credibility of a withholding strategy. As discussed in section 2, Groh's analysis fits only imperfectly into the current market structure. Our markets are not repeated infinitely and we introduce no explicit discount rate. Even more importantly, exchange in our markets is multilateral rather than bilateral. Sellers post prices to all buyers each period, and buyers can make purchases from different sellers. Thus, the considerations regarding switching costs that underlie Groh’s analysis do not directly apply here. Nevertheless, we emphasize that as a theoretical matter, withholding strategies do not obviously allow buyers to elicit lower prices.

\section{Experimental Design and Procedures.}

To gain some insight into the relationship between powerful buyers, synergies and postmerger prices, we conduct an experiment based on the market design developed in the preceding section. Prior to reviewing the structure of the experiment we offer two comments about the incentive structure induced by these designs. First, while costs and values in natural contexts are undoubtedly more complex than the supply and demand structures illustrated in Figures 1 and 2, the simplicity of our design facilitates laboratory investigation. A simple design both increases the transparency of the relevant incentives and facilitates our communicating the market

\footnotetext{
${ }^{26}$ Sessions in Tillman (1999) and Ruffle (2000) consisted of 20 periods. Engle-Warnick and Ruffle (2001) used 30 period markets. As explained below, our experiment consists of 50-period markets.
} 
structure to participants. Using starkly simple cost and value structures helps assure that telling buyers and sellers the underlying cost and value structure actually creates common knowledge about supply and demand conditions.

Second, we purposely make the effects of small amounts of withholding quite large. A long history of experimental research suggests that the one-sided nature of the posted-offer trading institution confers an immense advantage on sellers, the posting side of the market. Thus, we felt compelled to make considerable effort to give buyers good chance of affecting performance via withholding. ${ }^{27}$ We did not consider seriously the possibility that human buyers could drive prices to unit costs. As we report below, buyer efforts to reduce prices were sometimes surprisingly effective.

4.1 Experimental Design. The experiment consists of a series of 40 fifty-period posted-offer quadropolies. In thirty of the sessions, a pair of symmetric consolidations occurs halfway through each market, generating two large symmetric sellers post-merger. The remaining 10 sessions are control markets, where four sellers trade under constant conditions throughout the session. By and large, markets followed standard laboratory posted-offer procedures. Each period negotiations follow the standard sequence, with sellers first simultaneously posting price and maximum offer quantity decisions. Production is to order in the sense that sellers bear unit costs only for those units that subsequently sell. ${ }^{28}$ Seller posting decisions are followed by a shopping sequence, where buyers (simulated or real) make purchase decisions. Each period, once seller decisions are complete, the price choice of each seller (but not that sellers' maximum offer quantity) is made public to both buyers and to the other sellers. During the purchasing sequence, the seller observes as private information his or her sales as they occur. (The seller, however, does not observe the identity of the purchasing buyer.) As they make purchases, buyers observe the earnings consequences of each unit they purchase, as well as the sellers who still have stock remaining. Upon the completion of the shopping sequence, we re-endow participants with unit values and costs, and a subsequent period begins.

\footnotetext{
${ }^{27}$ Evidence from a variety of experimental studies where "real” buyers were used indicates that buyers in posted offer institutions tend to follow such “fully-revealing” rules almost uniformly (e.g., Davis and Williams, 1991, Ketcham, Smith and Williams, 1984, and Smith, 1981). Even in the full information experiments reported by Ruffle (2000) and Engle-Warnik and Ruffle (2003) prices fell only occasionally, despite considerable withholding.

28 Advance production would change importantly the analysis. For an analysis of the effects of advance production in a Bertrand-Edgeworth pricing game, see e.g. Tasnadi (2004).
} 
Market procedures deviate from standard posted-offer implementations in three respects. First, each seller bears a fixed cost each period. This cost is borne regardless of whether or not any units the seller offers subsequently sell. Second, to bound the sellers' exposure to fixed costs, we barred them from posting prices that would necessarily generate negative profits for the period. $^{29}$ Third, buyers and sellers were told as common knowledge unit values, unit costs and fixed costs.

Our treatments include the use of real or simulated buyers, the presence or absence of a consolidation, and the type of synergy induced. In twenty of the forty markets, we automated buying decisions. In these "simulated buyer" markets a single automated buyer purchases seven of the eight units offered, provided prices on each unit are $\$ 6$ or less. Each period, the simulated buyer purchases the least expensive units first, followed by progressively more expensive units. In 20 remaining "human buyer" markets, we endow two buyers with a total of seven units each period. We divide units evenly between buyers each period with the odd unit rotating between buyers across periods. On each unit purchased, human buyers earn the difference between their unit value of $\$ 6$ and the posted price. Unlike simulated buyers, the human buyers had no obligation to fully reveal demand, and could (and often did) forego purchases in a period. ${ }^{30}$

The presence or absence of a consolidation represents a second treatment dimension. In ten "control" markets the four sellers who make decisions for the first 25 periods continued, uninterrupted for an additional 25 periods. ${ }^{31}$ In 30 remaining sessions a monitor interrupts the session after period 25 and announces that consolidations have occurred. The sellers then each draw one of four cards labeled “A1”, “A2”, "M1” and "M2”. Sellers A1 and A2 become “acquired sellers” while sellers M1 and M2 each become "merged firms.” In these markets, sellers M1 and M2 each make price and quantity decisions for one of the two firms illustrated in the right panel of Figure 1, or in one of the panels of Figure 2. Acquired sellers A1 and A2

\footnotetext{
${ }^{29}$ The lower price bound is slightly below breakeven price $p_{b e}$, since at best only seven of the eight units offered each period will sell. Pre-merger, the minimum allowed price was \$3.51. Absent a synergy, the minimum price remained unchanged post-merger. With either a unit-cost or a fixed cost synergy, the minimum permissible postmerger price fell to $\$ 2.38$ per unit.

${ }^{30}$ Using two buyers rather than a single buyer allows us to conduct market sessions that do not turn entirely on the decisions of a single individual (the buyer). Dividing units among two buyers weakens somewhat each buyer's bargaining position, relative to the case of a single buyer. Nevertheless, buyers remain quite powerful, as either can unilaterally eliminate at least one seller from the market in any period, both pre-merger and post-merger.

${ }^{31}$ To improve comparability with procedures in the consolidation treatments, the control markets were paused briefly after period 25 . A monitor announced that the market would continue, exactly as before for an indefinite number of additional periods (which might or might not be followed by still other additional sequences).
} 
watch (but do not communicate with) M1 and M2, respectively, under the condition that M1 and M2 divide post-merger earnings equally with their acquired counterparts. ${ }^{32}$ The markets continue for another 25 periods. Both the consolidation and the end of the experiment occur without prior announcement. (In fact, post-merger participants were told not only that the final period of the second sequence would not be announced in advance, but also that the market might or might not contain yet other sequences.)

For the 30 “consolidation” sessions, synergies represent the third treatment dimension. In ten "no-synergy" markets, each seller's capacity doubles with the consolidation from two units to four, and fixed costs increase from $\$ 3$ to $\$ 6$ per period, as illustrated by the cost arrays in the right panel of Figure 2. In a second set of ten "fixed cost synergy" markets, fixed costs for the consolidated seller fall by $\$ 4.50$ from $\$ 6$ to $\$ 1.50$ per period. In ten remaining "unit cost synergy” markets, unit costs for the consolidated firm fall from $\$ 2.00$ to $\$ 0.71$ per unit, an amount that also generates expected savings of $\$ 4.50$ per period.

Table 1 summarizes the matrix of treatments. Our options of two consolidation conditions (merger or no-merger), two buyer types, and three possible synergies create twelve possible treatment cells. As Table 1 suggests we conduct five sessions in each treatment cell except for the four cells (uninteresting for the present purposes) where synergies occur absent a consolidation. Table 1 also introduces the two-part identifier we will use to refer to the different treatments. The first two letters "SB" or "RB" indicate the use of simulated or human buyers, respectively, while the final letters, "C", “N”, "F" or "U” indicate, respectively, control, no synergy, a fixed cost synergy or a unit cost synergy. Thus, for example, the identifier RBU in the lower right corner of the table refers to the five markets conducted with real buyers, where a unit cost synergy accompanied the consolidations.

4.2. Experimental Procedures. At the outset of each session, a monitor randomly seats student volunteers at visually isolated personal computers. The monitor then reads instructions aloud as participants follow along on a copy of their own. The instructions explain general market incentives, as well as the computerized posted-offer trading mechanism. After the monitor

\footnotetext{
${ }^{32}$ The merged seller splits earnings with an acquired seller in order to reduce the chances that post-merger price reductions might be driven by sellers and/or buyers regarding the consolidation as a pure windfall for the merging seller. Our procedure follows closely that used by Huck et al. (2001), except that unlike Huck et al. we prohibit communications between the merged seller and their acquired counterpart.
} 
answers participants' questions, the market commences. Except for two sessions, data were collected in simultaneously-conducted multiple markets.

Participants were students recruited from upper level undergraduate business and MBA classes at Virginia Commonwealth University in the spring semester of 2003 and in the summer term of 2004. We converted salient earnings from Lab dollars to U.S. currency at a rate of \$10 $\mathrm{Lab}=\$ 1$ US. In addition to their salient earnings, we paid participants a \$6 appearance fee for meeting their appointment. ${ }^{33}$ Also, sellers in the "human buyer" markets were given an ex post supplement of \$4-\$6. As will be evident below, seller earnings were far lower than what we expected ex ante, and we provided the ex post supplements in order to keep low earnings from discouraging participation by others. ${ }^{34}$ A total of 200 students participated in the 40 markets which each lasted between 60 and 95 minutes. No one participated in more than one market. Earnings ranged from $\$ 9.00$ to $\$ 55.50$ and averaged about $\$ 22.00$.

\section{Experimental Results}

The median price paths for the simulated buyer and real buyer treatments, shown respectively in the upper and lower panels of Figure 3, illustrate some of the primary experimental results. Looking first at the upper panel, notice that in the simulated-buyer markets, mergers clearly raise prices. Comparing the median price paths for the merger/nosynergy (SBN) sessions with the no-merger control (SBC) treatments, observe in the SBN markets that, despite starting somewhat above the median of the pre-merger static Nash mixing distribution, $\tilde{p}=\$ 4.43$, the price path clearly trends upward post-merger, toward the median of the post-consolidation mixing distribution, $\tilde{\rho}=\$ 5.43$. In contrast, the median price path in the SBC treatment hovers about the pre-merger static Nash prediction throughout the session. As suggested by the proximity of the SBF and SBN price paths post-merger, merger-associated fixed cost synergies do not affect performance. On the other hand, terminal prices for the SBU treatment suggest that unit cost synergies exert some power-mitigating effect. Notice, also however, that pre-merger prices in the SBU treatment lie below those in either the SBN or SBF

\footnotetext{
${ }^{33}$ In some instances more participants appeared that we could use in a session. Extra participants were identified as “alternates." Alternates were paid \$10 and were invited to come back in a subsequent session.

${ }^{34}$ Twenty-four of the 80 sellers in the real buyer sessions ended the session with negative salient earnings. Even with the $\$ 6$ appearance fee, 14 of these sellers would have earned less than $\$ 4.00$ for 1 to $1 \frac{1 / 2}{2}$ hours of their time.
} 
treatments, suggesting that less aggressive (or less tacitly collusive) sellers in the SBU treatment may drive the lower post-merger prices.

Median price paths for the real buyer sessions, shown in the bottom panel of Figure 3 tell a very different story. First, comparing across panels, observe that the presence of real buyers results in uniformly lower prices: Prices in the real buyer sessions either hover about the premerger Nash prediction $\tilde{p}=\$ 4.43$, or lie below it. Further, the median price paths exhibit either no obvious trend or trend downward post merger (particularly in the RBU treatment). The stable or downward-trending post-merger price paths in the RBN, RBF and RBU treatments suggests that real buyers fully offset market power, and in some instances may extract from sellers a portion of merger-associated synergies.

In the remainder of this section we evaluate more formally the results suggested by Figure 3. We proceed by evaluating in turn the five conjectures offered in the previous section. In the analysis that follows we focus on the median of posted prices for the final 10 periods of the initial (pre-consolidation) and terminal (post-consolidation) sequences. ${ }^{35}$ To analyze results, we compare both pre-merger and post-merger "levels", as well as the "differences," or the change in levels within sessions. These latter comparisons are often useful for identifying merger-associated treatment effects. Research hypotheses for pre- and post-merger levels, as well as for differences follow naturally from the statement of each conjecture. For clarity, we state the appropriate null hypothesis above each test result. Finally, for purposes of completeness, we report results of both nonparametric Mann-Whitney ('MW') tests as well as Fisher Exact Probability ('FEP') tests for comparisons of medians. The median prices upon which this analysis is based appear as tables A1 and A2 in the appendix.

Consider first the effects of merger-induced market power increases on prices in the simulated buyer markets. Table 2 summarizes the pertinent price information. As stated in conjecture 1 , in simulated buyer markets, prices should move directly with market power

\footnotetext{
${ }^{35}$ Thus, single data points are the median of posted-prices for all sellers in a session in periods $16-25$ and 41-50. We concentrate our attention on decisions in the last 10 periods to allow for learning at the outset of sessions, as well as to control for "restart" effects of the type observed by Andreoni (1988). We use median rather than mean prices as the unit of analysis, because the reference predictions in section 3 are developed in terms of median prices, and because the non-parametric tests we use to draw conclusions are tests of medians under more general circumstances than they are test of means. (Using a Mann-Whitney or a Fisher's Exact Probability test to test for the equality of means requires the assumption that the distribution of observations is symmetric. Symmetry is not required to use these tests to test for the equality of medians.) However, our results are robust to the selection of final period segment, and to the use of means rather than medians as the basis of analysis.
} 
increases. Pooling the SBN, SBF and SBU sessions into an 'SBM' cell identifying sessions where a merger occurs, observe that the pre-merger median price in the 15 SBM sessions, \$4.95, does not differ significantly from the pre-merger median of $\$ 4.75$ in the 5 simulated buyer control ('SBC') sessions (MW $p=.36$, FEP $p=1.00$ ). Post-merger, however, this difference does become significant, as the median price in the SBM sessions rises to $\$ 5.53$ and the median price for the SBC sessions falls to $\$ 4.59$ (MW $p=.01$, FEP $p=.02$ ). Similarly, notice in the rightmost column of Table 2 that the median post-merger price increase of $\$ 0.43$ in the SBM sessions significantly exceeds the median \$0.04 increase in the final ten periods of the SBC sessions (MW $p=.02$, FEP $p=.02$ ). To our knowledge, this is the first evidence that increasing existing seller market power raises prices. This is our first finding.

prices.

Finding 1: In simulated buyer markets, increasing market power via mergers raises

Consider next the effects of synergies on post-merger prices in the simulated buyer markets, the subject of conjecture 2. Table 3 summarizes median pre- and post-merger prices for the three simulated buyer treatments where a merger occurred. Notice in the upper row block of Table 3 that fixed costs synergies do nothing to reduce prices in the simulated buyer markets. The median pre-merger price of $\$ 5.50$ for the five simulated buyer/no synergy ('SBN') markets does not differ significantly from the median of $\$ 5.35$ for the five simulated buyer/ fixed cost synergy ('SBF') markets ( $\mathrm{MW} p=.67$, FEP $p=1.00$ ). Post-merger, median prices in the SBF markets actually exceed those in the SBN markets (\$5.83 vs. \$5.53). Mann Whitney test results suggest that this difference is significant, although results of the Fisher Exact Probability test do not also support such a conclusion (MW $p=.10$, FEP $p=.53$ ). Overall, the median post-merger price increase of $\$ 0.27$ for the SBF sessions does not differ significantly from the comparable median of $\$ 0.25$ for the SBN sessions (MW $p=.35$, FEP $p=1.00$ ).

On the basis of these results, we pool the SBN and SBF sessions, and compare median prices for a combined SBN/SBF ('SBNF') treatment with those for the SBU treatment (simulated buyers/unit cost synergies). As suggested by the middle column in the lower row block of Table 3, the median post-merger price of $\$ 5.80$ for the SBNF treatment significantly exceeds the mean post-merger price of $\$ 5.04$ for the SBU treatment (MW $p=.01$, FEP $p=.02$ ), suggesting that the unit cost synergies induced here mitigate merger-induced market power changes, as predicted. The pre-merger medians of \$5.42 and \$4.50 for the respective SBNF and 
SBU treatments, lead us to qualify this finding, as less aggressive sellers in the SBU sessions rather than synergies may also help explain lower median post-merger SBU prices. That said, low pre-merger prices in the SBU sessions say nothing definitive about either the aggressiveness of post-merger duopolists, or the price-tempering effect of unit cost synergies. ${ }^{36}$ To err on the side of caution, we draw here a qualified conclusion regarding the effect of unit cost synergies on post-merger pricing.

Finding 2. With simulated buyers, a large fixed cost synergy affects neither post-merger prices nor post-merger price increases. In contrast, post-merger prices are lower in the SBU markets characterized by a unit cost synergy than in the combined $S B N$ and SBF markets, suggesting that unit cost synergies reduce prices, as predicted. However, we also observe sellers in the $S B U$ treatment were more competitive pre-merger than in the other SBN/SBF markets.

Given the subtlety of the predicted unit cost synergy effect, we were somewhat surprised to observe even qualified support for a unit cost synergy here. Unlike the predicted increase in the mixing distribution induced by reducing the number of sellers from four to two, tacit collusion in the post-merger two seller markets merger would undermine the predicted effects of unit cost synergies.

Next we shift attention to the effects of using real buyers. First we evaluate the extent to which real buyers reduce prices, as articulated in Conjecture 3. Table 4 summarizes median price information for the 20 simulated buyer ('SB') sessions, and for the 20 real buyer ('RB') sessions. Reading across the columns observe that the pre-merger median price of $\$ 4.80$ in the SB sessions significantly exceeds the pre-merger median of $\$ 4.00$ in the RB sessions (MW $p=.001$, FEP $p=.001)$. Similarly the post-merger median price of $\$ 5.44$ in the SB sessions significantly exceeds the post-merger median of $\$ 4.18$ in the RB sessions (MW $p=.001$, FEP $p=.001$ ). Notice finally in the right column of Table 4 that post-merger median price increase of $\$ 0.52$ for the SB sessions significantly exceeds the $\$ 0.10$ price reduction in the RB sessions (MW $p=.01$, FEP $p=.06)$. Combined, these results support Conjecture 3, which is our third finding.

Finding 3: Inserting human buyers into these posted-offer markets reduces pre-merger prices, post-merger prices, and the difference between pre- and post-merger prices within markets.

\footnotetext{
${ }^{36}$ Indeed notice that the median increase for the SBU treatment of $\$ 0.52$ actually exceeds the median increase of $\$ 0.26$ for the SBNF treatments (albeit not significantly so), suggesting that the post-merger duopolists in the SBU sessions recognized and exploited their increased power.
} 
Consider next the extent to which real buyers reduce trading efficiency, the subject of Conjecture 4. The histograms shown in the two panels of Figure 4 list mean initial- and terminal-segment efficiencies (white bars and grey bars, respectively) for the last 10 periods of each segment. Comparing across the panels, notice that trading efficiencies are between 10\% and 25\% lower in the real buyer treatments than in each of the comparable simulated buyer treatments. Thus, while the use of real buyers reduces prices substantially, the negotiation process is uniformly costly in terms of foregone trading efficiency. Table 5 summarizes mean trading efficiencies aggregated across RB and SB treatments. As is clear from the table, mean trading efficiencies for the RB sessions are between 15 and 18 percentage points lower in the RB sessions than in the SB sessions (85\% vs. $100 \%$ in periods $16-25$ and $82 \%$ vs. $100 \%$ in periods 41-50), differences that are easily significant (in either segment comparison MW $p=.001$, FEP $p=.001$.) ${ }^{37}$ This is our fourth finding:

Finding 4: Powerful human buyers substantially reduce trading efficiency.

The persistence of withholding-induced trading efficiency losses in our markets extends results of previously reported experiments of somewhat shorter duration by Slembeck (1999), Ruffle (2000) and Ruffle and Engle-Warnik (2003), and suggests an important potential cost of these thin, full information market structures. Perhaps with time trading efficiency might increase as buyers come to credibly communicate their threats to withhold. At the least, however, trading efficiency losses appear to be neither small nor trivially transitory. To the contrary, as seen in the rightmost column of Table 5, mean trading efficiencies for the real buyer markets actually decreased by 4 percentage points in periods 41-50 relative to periods 16-25.

Our final conjecture regards the extent to which synergies affect pricing outcomes in real buyer markets. Table 6 presents pertinent information. Comparing median prices in the five real buyer/no synergy ('RBN') sessions with median prices in the five real buyer/fixed cost synergy ('RBF') sessions suggests that the presence of a fixed cost synergy does not reduce prices. In the RBN sessions, median prices fall from \$3.99 pre-merger to $\$ 3.94$ post merger. In the RBF markets median prices actually increase slightly $\$ 4.00$ to $\$ 4.17$. However, median prices do not differ significantly either pre-merger (MW $p=0.86$, FEP $p=0.52$ ) or post-merger (MW $p=0.25$,

\footnotetext{
${ }^{37}$ Notice that Table 5 lists mean rather than median trading efficiencies. The high frequency of periods where all possible gains from exchange were extracted makes mean trading efficiencies a more useful summary measure of trading efficiency outcomes.
} 
FEP $p=1.00$ ). Similarly, median post-merger price differences of $\$ 0.00$ for the RBN market and $-\$ 0.77$ for RBF market do not differ significantly (MW $p=0.33$, FEP $p=0.36$ ).

The bottom two row blocks of Table 6 evaluate alternative poolings of sessions that evaluate various possible synergy effects. First, we pool the RBN/RBF sessions into a single ('RBNF') treatment and compare median prices with the 5 real buyer/unit cost ('RBU') sessions. This pooling allows us to evaluate the extent to which unit cost rather than fixed cost synergies affect post merger behavior. As is clear from of the middle row block in Table 6, neither price levels, nor price level differences approach significance. For example, as seen in the rightmost column of the table, the median post-merger price reduction of \$0.19 in the RBNF treatment actually exceeds the $\$ 0.02$ median price reduction in the RBU treatment, making it impossible to conclude that buyers extract unit cost synergies (MW $p=.90$, FEP $p=.43$ )

The bottom row block of Table 6 pools into a single treatment prices in the two synergy treatments RBF/RBU ('RBUF') and compares prices with those in the no-synergy RFN treatment. This pooling allows evaluation of the (admittedly ad hoc) hypothesis that synergies induce increased aggression in buyers. Were this true, post-merger prices in the combined RBF/RBU ('RBUF') sessions should fall below those in the RFN treatment. Results of this comparison do not support such a "synergy" effect. The median post-merger price of \$3.94 in the RBN treatment exceeds the median post-merger price of \$3.84 in the RBUF only marginally and insignificantly (MW $p=0.39$, FEP $p=0.57$ ). Similarly, while the post-merger median price difference $-\$ 0.43$ in the RBUF treatment exceeds the median difference of $\$ 0.00$ in the RBN treatment, the treatment effect does not approach significance at conventionally accepted levels (MW $p=0.27$, FEP $p=0.43$ ). This is our fifth finding:

Finding 5: In the real buyer markets, neither fixed cost synergies nor unit cost synergies significantly affect median post-merger prices.

This negative result regarding the effects of synergies on post-merger prices in real buyer markets on a treatment level belies the fact prices that in several of the real buyer markets, particularly those in the RBF and RBU treatments, prices did fall very considerably post-merger. For example, in 5 of the $10 \mathrm{RBF}$ and $\mathrm{RBU}$ markets the median reduction in post-merger prices exceeded $\$ 0.75$. Thus, although buyers may not consistently extract merger-associated synergies, in many instances, they do. Prior to concluding this section we offer some observations regarding the relationship between buyer actions and prices, as a means of gaining 
some insight into heterogeneity of outcomes across treatments. Note first, that in several instances the buyer side of the market engaged in very substantial withholding. Figure 5 illustrates. The three panels of the figure plot median posted prices for the last 10 periods of a segment (initial or terminal) against the percentage of units in the entire segment that buyers collectively elected to not purchase. Notice that in several instances, buyers engaged in very considerable withholding. For example, as shown in the top panel, in the initial segment of the 20 real buyer markets, buyers withheld the purchase of at least $20 \%$ of the available units in 4 markets. Similarly, in the terminal segments, buyers withheld at least $20 \%$ of possible purchases in 2 of the 10 markets where no synergy occurred (shown in the middle panel) and in 4 of the 10 synergy markets. But buyer withholding was far from uniform across sessions. Notice also in Figure 5 that buyers withheld $5 \%$ or fewer of the available purchases in 4 of the 20 initial segments, and in 3 of the 20 terminal segments.

Second we observe that the consequences of demand withholding are far from uniform. Were it the case that establishing a reputation for withholding drives down prices, we should see a negative relationship between median prices for the final 10 periods of a segment, and total instances of withholding. But, as is obvious from the three panels of the figure, no such relationship exists either in the initial or in the terminal segments. Each of the panels illustrate instances where transactions prices remain relatively high despite very significant withholding (shown in the upper right quadrant of each panel), and instances where mean transactions prices were low, despite very limited withholding (shown in the lower left quadrant of each panel). The extreme heterogeneity of outcomes echoes results observed by Slembeck (1999) in an ultimatum game context, namely that the personalities of the participants importantly affect outcomes such thin markets. This is our final finding:

Finding 6: Outcomes are highly variable in the real buyer markets. Buyers withhold demand heterogeneously, and further, sellers respond heterogeneously to buyer withholding.

\section{Conclusions.}

This paper reports an experiment designed to assess the interrelationships between powerful buyers, mergers, and merger-induced synergies in a repeated Bertrand-Edgeworth context. Although human buyers appear to induce generally lower prices, we also find that the presence of human buyers generally undermines the comparative static predictions that follow from passive buyer models. Further, trading in the human buyer markets tends to be 
characterized by very considerable outcome variability, and by an overall reduction in trading efficiency.

Naturally occurring markets are, of course, considerably more complex than the very simple structures considered here. Nevertheless, results of our experiments, we believe, tentatively offer two implications for antitrust policy. First, given powerful buyers, the predictions in standard unilateral-effects policy models no longer provide a reasonable basis for evaluating the consequences of a merger. Rather, policy variants of more sophisticated models, such as the model recently proposed by Inderst and Wey (2003) must be developed. The policy recommendations generated by such models will necessarily be more nuanced than those arising from unilateral effects analysis, because a variety of features typically excluded in current unilateral effects analysis, such as the curvature of the market surplus function, and current and feasible production technologies become important. ${ }^{38}$ We believe that this is an area where continued experimental research can play an important role, particularly given the subtlety of the pertinent theoretical predictions. At present we are preparing an analysis that parallels the present study, but in a bargaining context that more closely matches the assumptions regarding institutional trading rules typically made by theorists in intermediate goods markets.

Second, in addition to the added complexity of these new models, our laboratory results suggest that outcomes in markets with thin buyer and seller sides may be both difficult to predict and may be characterized by considerable bargaining inefficiencies. Reducing a market to a small number of fully informed buyers and sellers changes the nature of interactions from decentralized market interactions to a relatively complex bargaining game. Outcomes in such markets may be expected to be determined more by the personalities and bargaining strengths of the relevant buyers and sellers, than by predictable underlying structural characteristics. Thus, while powerful buyers may ameliorate merger-induced market power increases, our results suggest that anticipating the effects of mergers in markets with real buyers may be even more difficult than in standard diffuse-buyer contexts.

\footnotetext{
${ }^{38}$ As Inderst and Wey observe, in bilateral oligopolies, buyers may merge to influence sellers' choice of technology. The possible links between consolidations and technology choice have been a matter of some concern to of U.S. antitrust authorities. For a review see Gilbert and Sunshine (1995).
} 


\section{References}

Andreoni, J. 1988. Why free ride: strategies and learning in public goods experiments. Journal of Public Economics 37, 291-304

Buchheit, S., Feltovich, N. 2005. The relationship between sunk cost and firms' pricing decisions: an experimental study. Mimeo, University of Houston.

Chipty, T. 1995. Horizontal integration for bargaining power: evidence from the cable television industry. Journal of Economics and Management Strategy 4, 375-397.

Chipty, T., Snyder, C. 1999. The role of firm size in bilateral bargaining: a study of the cable television industry. Review of Economics and Statistics 81, 326-340.

Cripps, M. W., Ireland, N. J. 1988. Equilibrium capacities in a market of fixed size. Mimeo., University of Warwick.

Davidson, C., Deneckere R. 1986. Long-run competition in capacity, short-run competition in price and the Cournot model. RAND Journal of Economics 17, 404-414.

Davis, D. D. 2002. Strategic interactions, market information and mergers in differentiated product markets: an experimental investigation. International Journal of Industrial Organization 20, 1277-1312.

Davis, D. D., Holt C.A., 1994. Market power and mergers in laboratory markets with posted prices. RAND Journal of Economics 25, 467-487.

Davis, D. D., Reilly, R. J., Wilson, B. J., 2003. Cost structures and Nash play in repeated Cournot games: An Experimental Investigation. Experimental Economics 6, 209-226.

Davis, D. D., Williams, A. W., 1991. The Hayek Hypothesis in experimental auctions: market power and institutional effects. Economic Inquiry 29, 261-274.

Davis, D. D., Williams, A. W., 1990. Market power and the institutional asymmetry of the posted offer trading institution. Economics Letters 34, 211-214.

Davis, D. D., Wilson, B. J. 2006. Equilibrium price dispersion, mergers and synergies: an experimental examination of differentiated product competition and the antitrust logit model. International Journal of the Economics of Business (forthcoming).

Davis, D. D., and Wilson, B. J., 2000. Firm-specific cost savings and market power exercise. Economic Theory 16, 545-565. 
Deneckere, R., Davidson C., 1985. Incentives to form coalitions with Bertrand competition. RAND Journal of Economics 16, 473-486.

Deneckere, R., Kovenock, D., 1996. Bertrand-Edgeworth duopoly with unit cost asymmetry, Economic Theory 8, 1-25.

Dobson, P. W., Waterson, M., 1997. Countervailing power and consumer prices. Economic Journal 107, 418-430.

Engle-Warnik, J., Ruffle, B.J., 2003. Buyer countervailing power versus monopoly power: evidence from experimental posted-offer markets. Mimeo., University of Oxford.

Farrell, J., Shapiro, C., 1990. Horizontal mergers: an equilibrium analysis. American Economic Review 80, 107-126.

Federal Trade Commission v. Cardinal Health, Inc., 12 F. Supp. 2d 34, 1998 U.S. Dist. LEXIS 11779, (D.D.C. 1998) (Sporkin, S.).

Federal Trade Commission v. McKesson Corp., 12 F. Supp. 2d 34, 1998 U.S. Dist. LEXIS 11779, (D.D.C. 1998) (Sporkin, S.).

Galbraith, J. K., 1952. American Capitalism: The Concept of Countervailing Power, Houghton Mifflin, Boston.

Gilbert, R., Sunshine, S.C., 1995. Incorporating dynamic efficiency concerns in merger analysis: the use of innovative markets. Antitrust Law Journal 63, 569-601.

Groh, C., 2004. Some factors affecting buyer power in a customer market. Mimeo., Mannheim University.

Guth, W, Schmittberger, R., Schwarz, B. 1982. An experimental analysis of ultimatum bargaining. Journal of Economic Behavior and Organization 3, 367-388.

Hoffman, E. McCabe, K., Schachat, K., Smith, V., 1994. Preferences, property rights and anonymity in bargaining games. Games and Economic Behavior 78, 346-380.

Holt, C. A. 1989. The exercise of market power in laboratory experiments. Journal of Law and Economics 32 (pt. 2), S107-S131.

Holt, C. A., Solis-Soberon, F., 1992. The Calculation of Mixed-Strategy Equilibria in Posted offer Markets. In Isaac, R. M. (Ed.) Research in Experimental Economics, vol. 5. JAI Press, Greenwich.

Horn, H., Wolinsky, A., 1988. Bilateral monopolies and incentives for merger. Rand Journal of Economics 19, 408-419. 
Huck, S., Konrad, K. A., Müeller, W., Normann, H., 2001. Mergers and the perception of market power: an experimental study,” Mimeo., University College, London.

Inderst, R., Wey, C., 2003. Bargaining, mergers and technology choice in bilaterally oligopolistic industries. RAND Journal of Economics 34, 1-19.

Ketcham, J., Smith, V., Williams, A.W., 1984. A comparison of posted-offer and double-auction pricing institutions. Review of Economic Studies 51, 595-614.

Kreps, D. M., Scheinkmann, J., 1983. Quantity precommitment and Bertrand competition. The Bell Journal of Economics 14, 326-338.

Lustgarten, S. H., 1975. The impact of buyer concentration in manufacturing industries. Review of Economics and Statistics 57, 125-132.

Normann, H., Ruffle, B.J., Snyder, C., 2003. Do buyer-size discounts depend on the curvature of the surplus function? Experimental tests of bargaining models” Mimeo., Royal Holloway College.

Osborne, M. J., Pitchik, C., 1986. Price competition in a capacity constrained duopoly. Journal of Economic Theory 38, 238-260.

Roth, A. E., 1995. Bargaining experiments. Ch. 4. in Kagel, J., and Roth A., (eds.) The Handbook of Experimental Economics, Princeton University Press, Princeton.

Ruffle, B. J., 2000. Some factors affecting demand withholding in posted-offer markets. Economic Theory 16, 529-544.

Slembeck, T., 1999. Reputations and fairness in bargaining: experimental evidence from a repeated ultimatum game with fixed opponents. Mimeo. University of St. Gallen.

Smith, V. L., 1981. An empirical study of decentralized institutions of monopoly restraint. In Quirk., J. and Horwich, G., (eds.) Essays in Contemporary Fields of Economics in Honor of E.T Weiler (1914-1979), Purdue University Press, West Lafayette. 83-106.

Stole, L. A. Zwiebel, J. 1996a. Intra-firm bargaining under non-binding contracts, Review of Economic Studies 63, 375-410.

Stole, L.A. and Zwiebel, J. 1996b. Organizational design and technology choice under intrafirm bargaining. American Economic Review 86, 88-102.

Tasnadi, A., 2004. Production in advance versus production to order. Journal of Economic Behavior and Organization 54, 191-204.

United States Department of Justice and Federal Trade Commission: Horizontal Merger Guidelines. (1997) 
United States v. Country Lake Foods, Inc., 754 F. Supp. 669 (D. Minn. 1990).

Wellford, C. P., 1990. Takeovers and Horizontal Mergers: Policy and Performance. Ph. D. Dissertation, University of Arizona.

Werden, G. J., Froeb, L. M., 1994. The effects of mergers in differentiated products industries: logit demand and merger policy. Journal of Law, Economics, and Organization 10, 407-426.

Wilson, B. J., 1998. What collusion? Unilateral market power as a catalyst for countercyclical markups. Experimental Economics 1, 133-145. 
Table 1. Matrix of Treatments

\begin{tabular}{cc|c|c|}
\hline \multicolumn{3}{c}{ No-Merger } \\
\hline \multirow{4}{*}{ Buyer Structure } & None & \multicolumn{1}{c}{ Fixed Cost } & Unit Cost \\
\cline { 2 - 4 } Simulated & $5 \mathrm{SBC}$ & & \\
& & & \\
\cline { 2 - 4 } Real Buyers & $5 \mathrm{RBC}$ & \\
\cline { 2 - 4 } & \multicolumn{3}{c}{ Synergy } \\
\hline \multirow{3}{*}{ Muyer Structure } & None & Fixed Cost & Unit Cost \\
\cline { 2 - 4 } Simulated & $5 \mathrm{SBN}$ & $5 \mathrm{SBF}$ & $5 \mathrm{SBU}$ \\
\cline { 2 - 4 } Real Buyers & $5 \mathrm{RBN}$ & $5 \mathrm{RBF}$ & $5 \mathrm{RBU}$ \\
\cline { 2 - 4 } & &
\end{tabular}

Table 2. Tests of Conjecture 1:SBM ( $n=15)$ vs. SBC $(n=5)$

\begin{tabular}{|c|c|c|c|c|c|c|c|c|c|}
\hline & \multicolumn{6}{|c|}{ Levels } & \multicolumn{3}{|c|}{ Differences } \\
\hline & \multicolumn{3}{|c|}{ Periods $16-25$} & \multicolumn{3}{|c|}{ Periods 41-50 } & \multicolumn{3}{|c|}{ Periods $41-50$ vs. Periods $16-25$} \\
\hline & $\mathrm{H}_{\mathrm{o}}$ & & & $\mathrm{H}_{\mathrm{o}}$ & & & $\mathrm{H}_{\mathrm{O}}$ & & \\
\hline & $\tilde{p}_{S B M}=\tilde{p}_{S B C}$ & MW & FEP & $\tilde{p}_{S B M} \leq \tilde{p}_{S B C}$ & MW & FEP & $\Delta \tilde{p}_{S B M} \leq \Delta \tilde{p}_{S B C}$ & MW & FEP \\
\hline$\tilde{p}_{S B C}$ & 4.75 & 0.92 & & 4.59 & 2.58 & & 0.04 & 2.14 & \\
\hline$\tilde{p}_{S B M}$ & 4.95 & $(0.36)$ & $(1.00)$ & 5.53 & $(0.01)$ & $(0.02)$ & 0.43 & $(0.02)$ & $(0.02)$ \\
\hline
\end{tabular}


Table 3. Tests of Conjecture 2: SBN SBF and SBU

Levels

Periods 16-25
Periods 41-50
Differences

Periods 41-50 vs. Periods 16-25

SBN (n=5) v. SBF $(n=5)$

\begin{tabular}{ccccccccc}
$\tilde{H}_{\mathrm{o}}$ & \multicolumn{9}{c}{$\mathrm{H}_{\mathrm{o}}$} & \multicolumn{3}{c}{$\mathrm{H}_{\mathrm{o}}$} \\
$\tilde{p}_{S B N}=\tilde{p}_{S B F}$ & $\mathrm{MW}$ & FEP & $\tilde{p}_{S B N}=\tilde{p}_{S B F}$ & $\mathrm{MW}$ & FEP & $\Delta \tilde{p}_{S B N}=\Delta \tilde{p}_{S B F}$ & $\mathrm{MW}$ & FEP \\
5.50 & -0.42 & & 5.53 & -1.67 & & 0.25 & 0.94 & \\
5.35 & $(0.67)$ & $(1.00)$ & 5.83 & $(0.10)$ & $(0.53)$ & 0.27 & $(0.35)$ & $(1.00)$ \\
\hline
\end{tabular}

SBNF $(n=10)$ v. SBU $(n=5)$

\begin{tabular}{|c|c|c|c|c|c|c|c|c|c|}
\hline & $\mathrm{H}_{\mathrm{o}}$ & & & $\mathrm{H}_{\mathrm{o}}$ & & & $\mathrm{H}_{\mathrm{o}}$ & & \\
\hline & $\tilde{p}_{S B N F}=\tilde{p}_{S B U}$ & MW & FEP & $\tilde{p}_{S B N F} \leq \tilde{p}_{S B U}$ & MW & F EP & $\Delta \tilde{p}_{S B N F} \leq \Delta \tilde{p}_{S B U}$ & MW & FEP \\
\hline $\begin{array}{l}p_{S B N F} \\
\tilde{p}_{S B U}\end{array}$ & $\begin{array}{l}5.42 \\
4.50\end{array}$ & $\begin{array}{c}1.72 \\
(0.08)\end{array}$ & (0) & $\begin{array}{l}5.80 \\
5.04\end{array}$ & 2.57 & (0) & $\begin{array}{l}0.26 \\
0.52\end{array}$ & $\begin{array}{c}0.49 \\
(0.62)\end{array}$ & $(0.90)$ \\
\hline
\end{tabular}

Notes MW denotes a Mann Whitney test, and "FEP” denotes a Fisher Exact Probability Test for the equality of medians. Tests are twotailed when $\mathrm{H}_{\mathrm{o}}$ is stated as an equality, and one-tailed otherwise.

Table 4. Tests of Conjecture 3: SB $(n=20)$ vs. RB $(n=20)$

Levels

\begin{tabular}{ccc}
\hline \multicolumn{3}{c}{ Periods $16-25$} \\
\hline $\mathrm{H}_{0}$ & \\
$\tilde{p}_{S B} \leq \tilde{p}_{R B}$ & $\mathrm{MW}$ & $\mathrm{FE}$ \\
4.80 & $\mathbf{3 . 9 8}$ & \\
& & \\
4.00 & & $\mathbf{( 0 . 0 0 )}$
\end{tabular}

\section{Levels}

$\tilde{p}_{S B}$

$\sim \mathrm{H}_{0}$

Periods 41-50

$\mathrm{H}_{\mathrm{O}}$

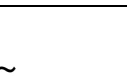
$\tilde{p}_{R B}$

FEP

$$
\tilde{p}_{S B} \leq \tilde{p}_{R B} \quad \text { MW } \quad \text { FEP }
$$

5.44

4.18

(0.00)
Differences

Notes "MW" denotes a Mann Whitney Test, and "FEP" denotes a Fisher Exact Probability test for the equality of medians. Tests are two-tailed when $\mathrm{H}_{\mathrm{o}}$ is stated as an equality, and one-tailed otherwise. 
Table 5. Tests of Conjecture 4: SB $(n=20)$ vs. RB $(n=20)$

Levels

\begin{tabular}{|c|c|c|c|c|}
\hline \multicolumn{3}{|c|}{ Periods 16-25 } & \multicolumn{2}{|c|}{ Periods $41-50$} \\
\hline $\mathrm{H}_{\mathrm{o}}$ & & & $\mathrm{H}_{\mathrm{o}}$ & \\
\hline $\bar{E}_{S B} \leq \bar{E}_{R B}$ & MW & FEP & $\bar{E}_{S B} \leq \bar{E}_{R B}$ & MW \\
\hline 1.00 & 5.42 & & 1.00 & 4.20 \\
\hline 0.85 & $(0.00)$ & $(0.00)$ & 0.82 & $(0.00)$ \\
\hline
\end{tabular}

Differences

Periods 41-50 vs. Periods 16-25

$\mathrm{H}_{0}$

$\Delta \bar{E}_{S B} \leq \Delta \bar{E}_{R B} \quad \mathrm{MW} \quad$ FEP

$0.00 \quad 0.37$

$-0.04$

Notes "MW" denotes a Mann Whitney Test, and "FEP" denotes a Fisher Exact Probability test for the equality of medians. Tests are two-tailed when $\mathrm{H}_{\mathrm{o}}$ is stated as an equality, and one-tailed otherwise.

Table 6. Tests of Conjecture 5: RBN, RBF and RBU

Levels

\section{Periods 16-25}

Periods 41-50
Differences

Periods $41-50$ vs. Periods $16-25$

RBN (n=5) v. RBF (n=5)

$\mathrm{H}_{0}$ :

$$
\tilde{p}_{R B N}=\tilde{p}_{R B F}
$$

$\mathrm{H}_{0}$ :

$\tilde{p}_{R B N}$

$\tilde{p}_{R B F}$

$$
3.99
$$

4.00

0.86

(0.39) (0.52)

$\tilde{p}_{R B N}=\tilde{p}_{R B F}$

MW

3.94

4.17

0.25

$(0.81)$

(1.00)

FEP

$$
\Delta \tilde{p}_{R B N}=\Delta \tilde{p}_{R B F}
$$

MW

FEP

0.00

$-0.77$

RBNF ( $n=10)$ v. RBU $(n=5)$

\begin{tabular}{ccccccccccc}
\multicolumn{1}{c}{$\mathrm{H}_{\mathrm{o}}:$} & \multicolumn{1}{c}{$\mathrm{H}_{0}:$} & \multicolumn{3}{c}{$\mathrm{H}_{0}:$} \\
& $\tilde{p}_{R B N F}=\tilde{p}_{R B U}$ & $\mathrm{MW}$ & $\mathrm{FEP}$ & $\tilde{p}_{R B N F} \leq \tilde{p}_{R B U}$ & $\mathrm{MW}$ & $\mathrm{FEP}$ & $\Delta \tilde{p}_{R B N F} \geq \Delta \tilde{p}_{R B U}$ & $\mathrm{MW}$ & FEP \\
$\tilde{p}_{R B N F}$ & 3.99 & 1.04 & & 4.06 & 0.86 & & -0.19 & 0.12 & \\
$\tilde{p}_{R B U}$ & 3.73 & $(0.29)$ & $(0.29)$ & 3.50 & $(0.46)$ & $(0.57)$ & -0.02 & $(0.90)$ & $(0.43)$
\end{tabular}

RBN (n=5) v. RBUF ( $n=10)$

$$
\mathrm{H}_{\mathrm{o}} \text { : }
$$

$\tilde{p}_{R B N}=\tilde{p}_{R B U F} \quad$ MW $\quad$ FEP $\quad \tilde{p}_{R B N} \leq \tilde{p}_{R B U F} \quad$ MW $\quad$ FEP $\quad \Delta \tilde{p}_{R B N} \leq \Delta \tilde{p}_{R B U F} \quad$ MW $\quad$ FEP

$\tilde{p}_{R B N}$

$\tilde{p}_{\text {RBUF }}$

3.99

0.49

3.94

0.85

0.00

1.10

$-0.43$

$(0.27) \quad(0.43)$

Notes "MW" denotes a Mann Whitney Test, "FEP” denotes a Fisher Exact Probability Test for the equality of medians. Tests are twotailed when $\mathrm{H}_{0}$ is stated as an equality, and one-tailed otherwise. 



Figure 1. Symmetric Pre- and Post-Merger Designs
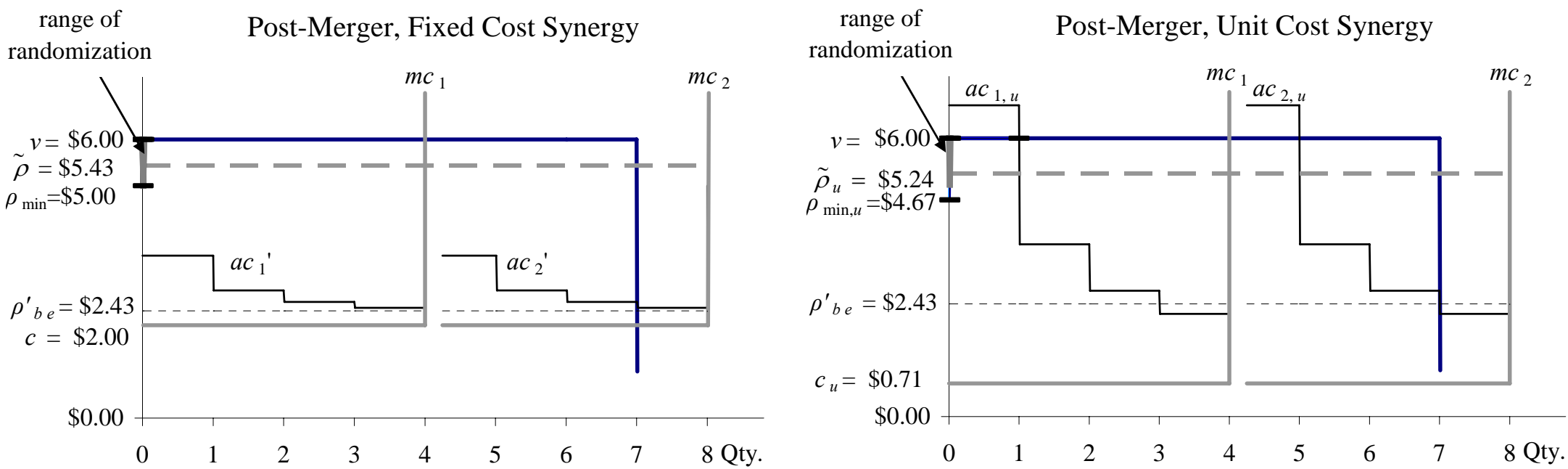

Figure 2. Synergies and Post-Merger Predictions 

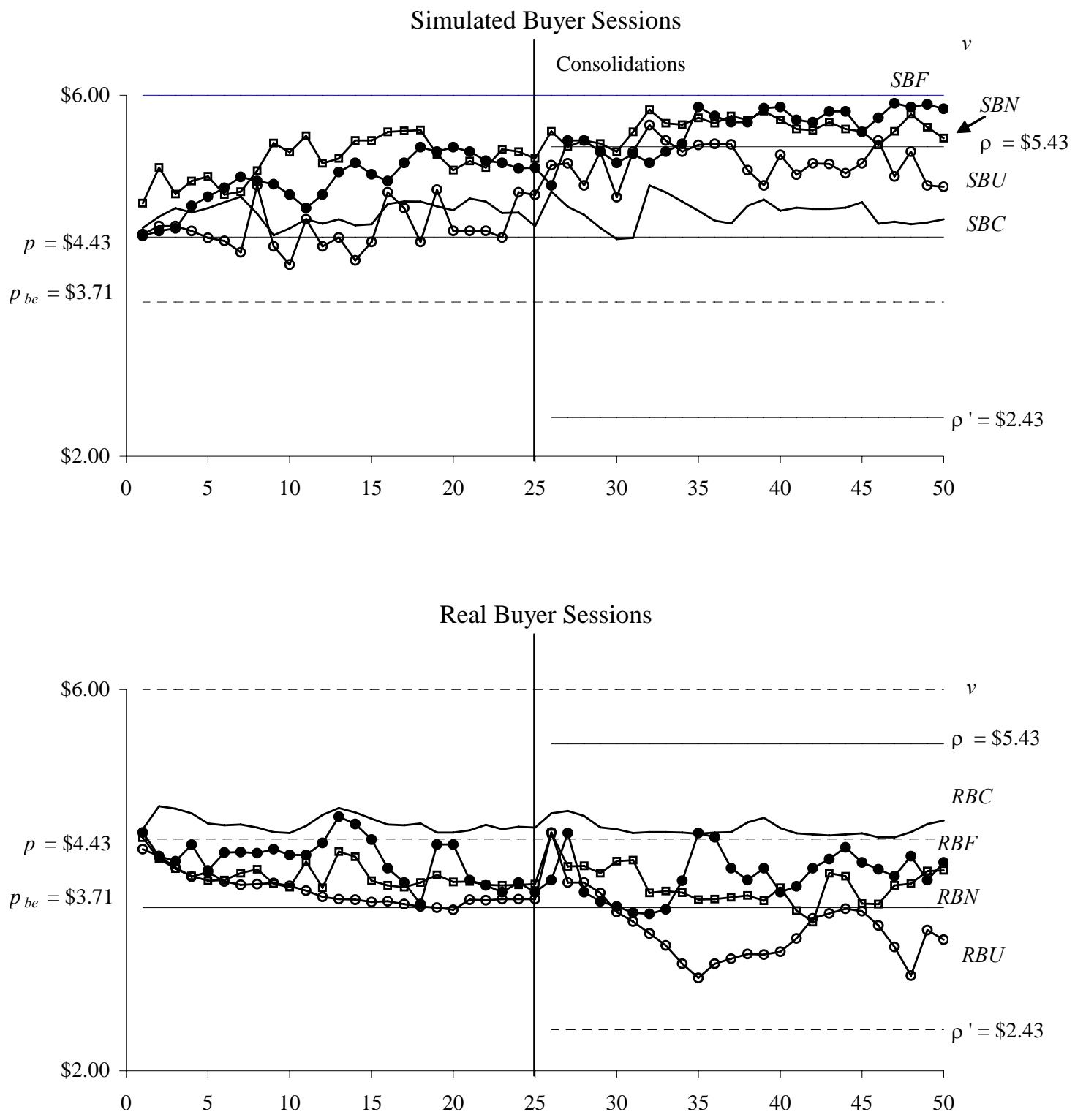

Figure 3. Median Price Paths by Treatment Key: Each line denotes the path of median posted prices for the five markets in each treatment. The upper panel illustrates price paths for the four simulated buyers (SB), while the lower panel illustrates price paths for the four real buyer (RB) treatments. In each panel the latter portion of the mnemonic, "C", "N", "F" or "U" denotes, respectively, control (no merger), no synergy, a fixed cost synergy or a unit cost synergy, respectively. 

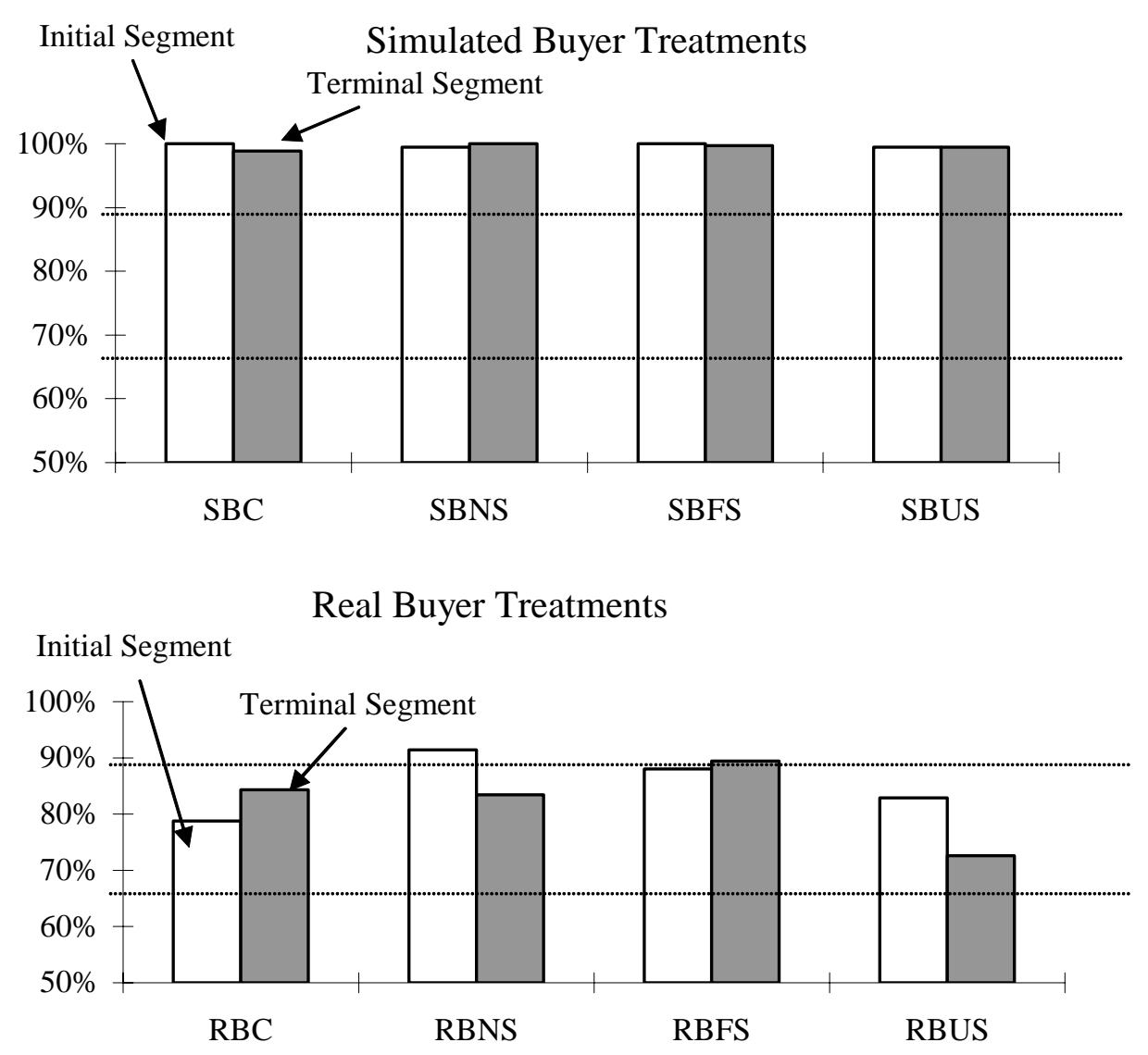

Figure 4. Mean Trading Efficiencies by Treatment. Key: Each bar illustrates the mean trading efficiency for a treatment, over the last 10 periods of a segment 


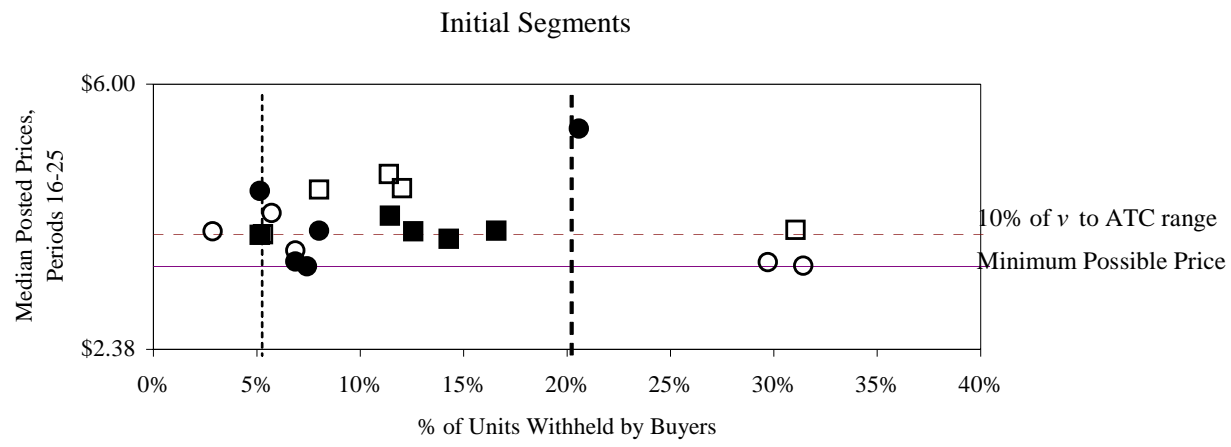

Terminal Segment - No Synergies



Terminal Segment -Synergies

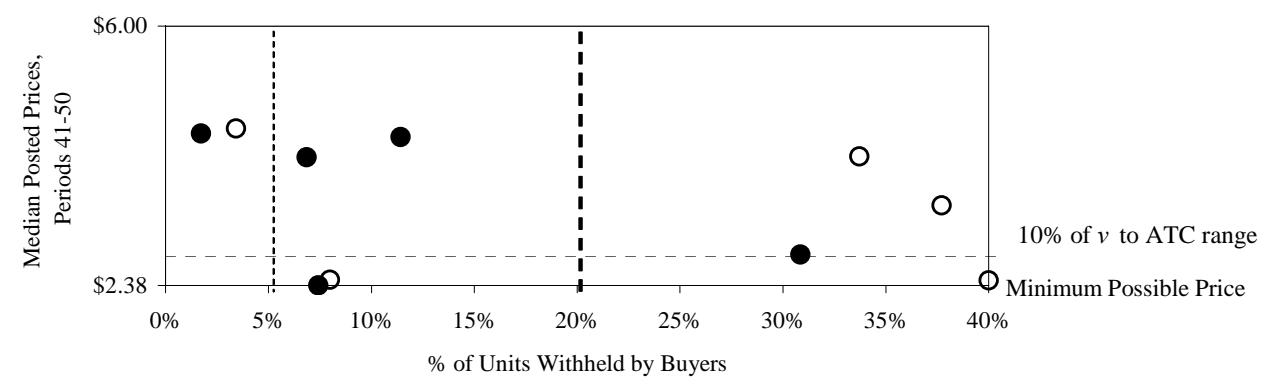

Figure 5. Buyer Withholding and Median Prices. Key: Each marker plots the median posted price for the final 10 periods of a market against the percentage of availabe units not purchased by buyers throughout the segment.

' $\square$ ' indicates an RBC session (no merger, no synergy)
' $\square$ ' indicates an RBN session (merger, no synergy)
' $\bullet$ indicates an RBF session (merger, fixed cost synergy)
'o' indicates an RBU session (merger, unit cost synergy) 


\begin{tabular}{|l|c|c|c|}
\hline \multicolumn{4}{|c|}{$\begin{array}{l}\text { Table A1 Simulated Buyer Treatments. Median Posted Prices, Last 10 Periods Initial and } \\
\text { Terminal Segments }\end{array}$} \\
\hline $\begin{array}{c}\text { (a) } \\
\text { Market }\end{array}$ & $\begin{array}{c}\text { (b) } \\
\text { Initial Segment } \\
\text { (Periods 16-25) }\end{array}$ & $\begin{array}{c}\text { (c) } \\
\text { Terminal Segment } \\
\text { (Periods 41-50) }\end{array}$ & $\begin{array}{c}\text { (d) } \\
\text { Price Change } \\
\text { (c) - (b) }\end{array}$ \\
\hline SBC1 & $\mathbf{5 . 2 0}$ & $\mathbf{5 . 2 4}$ & 0.04 \\
SBC2 & $\mathbf{4 . 8 5}$ & $\mathbf{4 . 5 2}$ & -0.33 \\
SBC3 & $\mathbf{4 . 1 0}$ & $\mathbf{4 . 0 0}$ & -0.10 \\
SBC4 & $\mathbf{4 . 7 5}$ & $\mathbf{4 . 8 5}$ & 0.10 \\
SBC5 & $\mathbf{4 . 4 3}$ & $\mathbf{4 . 5 9}$ & 0.16 \\
& & & -0.25 \\
\hline SBN1 & $\mathbf{5 . 7 0}$ & $\mathbf{5 . 4 5}$ & 0.79 \\
SBN2 & $\mathbf{5 . 0 1}$ & $\mathbf{5 . 8 0}$ & 0.03 \\
SBN3 & $\mathbf{5 . 5 0}$ & $\mathbf{5 . 0 3}$ & 0.43 \\
SBN4 & $\mathbf{4 . 6 0}$ & $\mathbf{5 . 8 5}$ & 0.25 \\
SBN5 & $\mathbf{5 . 6 0}$ & $\mathbf{5 . 6 0}$ & 0.27 \\
& & $\mathbf{5 . 8 3}$ & 1.61 \\
\hline SBF1 & $\mathbf{5 . 3 3}$ & $\mathbf{5 . 9 9}$ & 1.80 \\
SBF2 & $\mathbf{4 . 2 2}$ & $\mathbf{5 . 8 9}$ & 0.14 \\
SBF3 & $\mathbf{4 . 1 9}$ & $\mathbf{5 . 8 0}$ & 0.20 \\
SBF4 & $\mathbf{5 . 7 5}$ & & \\
SBF5 & $\mathbf{5 . 6 0}$ & $\mathbf{5 . 4 7}$ & 0.52 \\
& & $\mathbf{5 . 0 0}$ & 0.45 \\
\hline SBU1 & $\mathbf{4 . 9 5}$ & $\mathbf{5 . 0 4}$ & 0.64 \\
SBU2 & $\mathbf{4 . 5 5}$ & $\mathbf{5 . 4 3}$ & 1.13 \\
SBU3 & $\mathbf{4 . 4 0}$ & & \\
SBU4 & $\mathbf{4 . 5 0}$ & & \\
SBU5 & $\mathbf{4 . 2 5}$ & & \\
& & & \\
\hline
\end{tabular}


Table A2 Real Buyer Treatments. Median Posted Prices, Last 10 Periods Initial and Terminal Segments

\begin{tabular}{|c|c|c|c|}
\hline $\begin{array}{c}\text { (a) } \\
\text { Market }\end{array}$ & $\begin{array}{l}\text { (b) } \\
\text { Initial Segment } \\
\text { (Periods 16-25) }\end{array}$ & $\begin{array}{c}\text { (c) } \\
\text { Terminal Segment } \\
\text { (Periods 41-50) }\end{array}$ & $\begin{array}{c}(d) \\
\text { Med. Price } \\
\text { Change } \\
\end{array}$ \\
\hline RBC1 & 4.01 & 4.22 & 0.21 \\
\hline RBC2 & 3.95 & 3.78 & -0.17 \\
\hline RBC3 & 4.77 & 4.65 & -0.12 \\
\hline RBC4 & 4.58 & 4.80 & 0.22 \\
\hline RBC5 & 4.56 & 4.46 & -0.10 \\
\hline RBN1 & 4.20 & 5.04 & 0.84 \\
\hline RBN2 & 3.89 & 3.60 & -0.29 \\
\hline RBN3 & 3.94 & 3.94 & 0.00 \\
\hline RBN4 & 3.99 & 4.20 & 0.21 \\
\hline RBN5 & 4.00 & 3.54 & -0.46 \\
\hline RBF1 & 5.39 & 4.17 & -1.22 \\
\hline RBF2 & 4.54 & 4.45 & -0.09 \\
\hline RBF3 & 4.00 & 4.50 & 0.50 \\
\hline RBF4 & 3.58 & 2.81 & -0.77 \\
\hline RBF5 & 3.51 & 2.38 & -1.13 \\
\hline RBU1 & 3.57 & 2.45 & -1.12 \\
\hline RBU2 & 3.73 & 4.18 & 0.45 \\
\hline RBU3 & 3.99 & 2.46 & -1.53 \\
\hline RBU4 & 3.52 & 3.50 & -0.02 \\
\hline RBU5 & 4.24 & 4.57 & 0.33 \\
\hline
\end{tabular}

